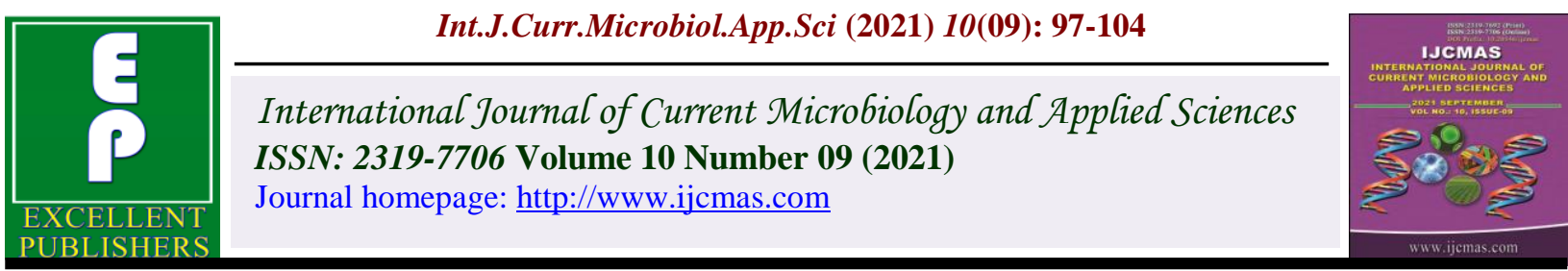

\title{
A Study to Compare the Production and Productivity of Rice Crop Between the BGREI Beneficiary Farmers and Non-Beneficiary Farmers in Odisha
}

\author{
Anannya Jena*
}

Krishi Vigyan Kendra, Odisha University of Agriculture and Technology, Sambalpur, India

*Corresponding author

\section{A B S T R A C T}

\section{Keywords \\ Production, \\ Productivity, \\ Beneficiary, Non- \\ beneficiary, \\ Demonstration, \\ Sustainable, \\ Interventions \\ Article Info \\ Accepted: \\ 10 August 2021 \\ Available Online: \\ 10 September 2021}

India is marching ahead to face the enormous triple challenges of sustainable increased agriculture and allied sector productivity, maintaining environmental sustainability and mitigating poverty. More than $70 \%$ rural households depend on agriculture and the contribution of Agriculture and allied sectors to total GDP (Gross Domestic Product) is $17 \%$. The agriculture and allied sector not only meet the food and nutritional requirements of 1.3 billion Indian, it contributes significantly to production, employment and demand generation through various backward and forward linkage. To extend the benefit of first green revolution (1966-67) and to reduce the yield gap Bringing Green Revolution in Eastern India programme was launched under RKVY (Rashtriya Krishi Vikas Yojana) in 2010-11 comprising seven states namely Bihar, Eastern UP, Jharkhand, Odisha, Assam, Chhatisgarh and West Bengal. There was a need for a second green revolution to feed the growing population. The present study was conducted during 2020-21 in two blocks namely Jamankira and Jujomura in Sambalpur district of Odisha to compare the production and productivity of rice crop between the BGREI beneficiary and non beneficiary farmers. During 2012-13 and 2013-14, the BGREI programme was extended to 22 districts of Odisha and National Rice Research Institute (previously CRRI), Cuttack, Odisha is the nodal agency to guide, supervise, monitor and supervise technical interventions. BGREI consists of the following interventions such as (i) Block demonstration (ii) Asset building (iii) Site specific activities (iv) Marketing support including post harvest management (v) Seed production and distribution (vi) Subsidy on need based inputs (vii) Training programme on cropping system based demonstration etc.

\section{Introduction}

With the increased population and overexploitation of land and other natural resources, the pressure on food production is increasing day by day. Around $65 \%$ of the total population live in villages and $70 \%$ of them depend solely on Agriculture for their living. In mid 1960s, Green revolution started, that was suitable for irrigated areas, but most of the area under farming in our country is rainfed. Apart from this green revolution was 
confined to increase food production but there was no provision for taking care of environment. The emergence of BGREI is to boost food production in eastern part of India that largely remained untouched in Green revolution that converted the north-west into a 'grain bowl'. BGREI is a flagship programme under Rashtriya Krishi Vikas Yojana (RKVY). It is started to address the constraints limiting the productivity of "rice based cropping systems". The BGREI program was announced in the Union Budget, 2010-11. BGREI primely focuses on bringing the second Green Revolution in eastern parts, which has rich water resources. Assam, Bihar, Chhattisgarh, Jharkhand, Odisha, West Bengal and eastern Uttar Pradesh (Purvanchal) are the seven states. Father of Indian Green Revolution Prof. M.S. Swaminathan called the government approach to the second Green Revolution "technocratic", with the sole emphasis on hybrid rice and also stress on the other aspects, particularly water management, assured irrigation and soil health management. Mr. Mukesh Khullar, Joint secretary of Union Agriculture and Farmers Welfare Ministry, and BGREI Programme Director said that the only way to ensure food security, a concern of every Indian, is to grow enough food grains domestically. The East was selected for the project essentially to harness the region's "abundant water resources", necessary to enhance the production of food grains. Prof. M.S. Swaminathan also said that water management is the main problem in eastern India, not water availability (Anonymous, 2012).

\section{Materials and Methods}

Sambalpur district in Odisha is one of the agricultural potential district in Odisha. BGREI programme has been running in Sambalpur district successfully since 2013-14. A sample of 300 farmers (150 BGREI beneficiaries and 150 non beneficiaries) from
8 villages of 4 gram panchayats under Jamankira and Jujomura block of Sambalpur were selected through Stratified Proportionate Random sampling method. The data was collected personally through a semi structural interview schedule pre-tested earlier. Out of total 9 blocks of Sambalpur district, 2 blocks implemented with BGREI were selected randomly in consultation with Krishi Vigyan Kendra(KVK) scientists and district agriculture officers for the study.

\section{Results and Discussion}

The data were collected through the interview schedule on the basis of objectives of the study. The data collected were classified, tabulated, analyzed, presented, interpreted and discussed systematically.

\section{Beneficiaries and non beneficiaries are distributed according to their rice production in different agro ecological situation.}

\section{Production of low land paddy}

BGREI beneficiaries and non beneficiaries are distributed according to their production of low land paddy.

Beneficiaries $(\mathrm{N})=150$, Non beneficiaries $(\mathrm{N})=150$

The table shows the percentage of production of low land paddy along with level of significant difference in production of low land paddy among BGREI beneficiary and non beneficiary farmers. It was observed that, among low, medium and high production category beneficiary and non beneficiary farmers there is significant difference in production with critical ratio $6.125^{* *}, 5.885^{* *}$ and $3.093^{* *}$ respectively. So there is significant impact by BGREI on all the production category of beneficiary farmers. 
Therefore, it is concluded by the researcher that the line dept. officials and other extension functionaries had properly provided training and technology demonstration programme to all the production category of BGREI farmers.

\section{Production of medium land paddy}

BGREI beneficiaries and non beneficiaries are distributed according to their production of medium land paddy.

Beneficiaries $(\mathrm{N})=150$, Non beneficiaries $(\mathrm{N})=150$

The table shows the percentage of production of medium land paddy along with level of significant difference in production of medium land paddy among BGREI beneficiary and non beneficiary farmers. It was observed that, among low, medium and high production category beneficiary and non beneficiary farmers there is significant difference in production with critical ratio $5.668^{*}, 6.206^{* *}$ and $3.305^{* *}$ respectively. So there is significant impact by BGREI on all the production category of beneficiary farmers.

Therefore, it is concluded by the researcher that the line dept. officials and other extension functionaries had properly provided training and technology demonstration programme to all the production category of BGREI farmers.

\section{Production of Up land paddy}

BGREI beneficiaries and non beneficiaries are distributed according to their production of $\mathrm{Up}$ land paddy.

Beneficiaries $(\mathrm{N})=150$, Non beneficiaries $(\mathrm{N})=150$

The table shows the percentage of production of up land paddy along with level of significant difference in production of up land paddy among BGREI beneficiary and non beneficiary farmers. It was observed that, among low, medium and high production category beneficiary and non beneficiary farmers there is significant difference in production with critical ratio $6.649 * 5.343 * *$ and $3.305^{* *}$ respectively. So there is significant impact by BGREI on all the production category beneficiary farmers.

Therefore, it is concluded by the researcher that the line dept. officials and other extension functionaries had properly provided training and technology demonstration programme to all the production category of BGREI farmers.

\section{Production of Kharif paddy}

BGREI beneficiaries and non beneficiaries are distributed according to their production of kharif paddy.

Beneficiaries $(\mathrm{N})=150$, Non beneficiaries $(\mathrm{N})=150$

The table shows the percentage of production of kharif paddy along with level of significant difference in production of kharif paddy among BGREI beneficiary and non beneficiary farmers. It was observed that, among low and medium production category beneficiary and non beneficiary farmers there is significant difference in production with critical ratio $6.949 * *$ and $6.934 * *$ respectively. So there is significant impact by BGREI on low and medium production category beneficiary farmers. But in high production category $\mathrm{CR}$ found to be 2.841 among BGREI beneficiary and non beneficiary farmers with no significant difference in production. Therefore, it is concluded by the researcher that the line dept. officials and other extension functionaries should provide training and technology demonstration programme to high production category of BGREI farmers. 


\section{Production of Rabi paddy}

BGREI beneficiaries and non beneficiaries are distributed according to their production of rabi paddy.

Beneficiaries $(\mathrm{N})=150$, Non beneficiaries $(\mathrm{N})=150$

The table shows the percentage of production of rabi paddy along with level of significant difference in production of rabi paddy among BGREI beneficiary and non beneficiary farmers.

It was observed that, among low, medium and high production category beneficiary and non beneficiary farmers there is significant difference in production with critical ratio $6.036^{* *}, 6.107^{* *}$ and $3.219^{*}$ respectively. So there is significant impact by BGREI on all the production category of beneficiary farmers.

Therefore, it is concluded by the researcher that the line dept. officials and other extension functionaries had properly provided training and technology demonstration programme to all the production category of BGREI farmers.

Beneficiaries and non beneficiaries are distributed according to rice productivity in different agro ecological situation.

\section{Productivity of low land paddy}

BGREI beneficiaries and non beneficiaries are distributed according to productivity of low land paddy in their farm.

Beneficiaries $(\mathrm{N})=150$, Non beneficiaries $(\mathrm{N})=150$
The table shows the percentage of productivity of low land paddy along with level of significant difference in productivity of low land paddy among BGREI beneficiary and non beneficiary farmers. It was observed that, among low, medium and high productivity category beneficiary and non beneficiary farmers there is significant difference in productivity with critical ratio $6.634 * *$, $6.649 * *$ and $2.950 *$ respectively. So there is significant impact by BGREI on all the productivity category of beneficiary farmers.

Therefore, it is concluded by the researcher that the line dept. officials and other extension functionaries had properly provided training and technology demonstration programme to all the productivity category of BGREI farmers.

\section{Productivity of medium land paddy}

BGREI beneficiaries and non beneficiaries are distributed according to productivity of medium land paddy in their farm.

Beneficiaries $(\mathrm{N})=150$, Non beneficiaries $(\mathrm{N})=150$

The table shows the percentage of productivity of medium land paddy along with level of significant difference in productivity of medium land paddy among BGREI beneficiary and non beneficiary farmers. It was observed that, among low, medium and high productivity category beneficiary and non beneficiary farmers there is significant difference in productivity with critical ratio $6.036^{* *}, 6.193^{* *}$ and $3.195^{*}$ respectively. So there is significant impact by BGREI on all the productivity category of beneficiary farmers. 
Table.1 Production of low land paddy

\begin{tabular}{|c|c|c|c|}
\hline Production & Beneficiary & Non beneficiary & CR Ratio \\
\hline Category & P1 & P2 & \\
\hline $\operatorname{Low}(\%)$ & $8.7(\mathrm{n} 1=150)$ & $41.3(\mathrm{n} 2=150)$ & $6.125^{* *}$ \\
\hline Medium(\%) & $14.7(\mathrm{n} 1=150)$ & $37.3(\mathrm{n} 2=150)$ & $5.885^{* *}$ \\
\hline $\operatorname{High}(\%)$ & 76.7(n1=150) & $21.3(\mathrm{n} 2=(150)$ & $3.093^{* *}$ \\
\hline
\end{tabular}

Table.2 Production of medium land paddy

\begin{tabular}{|c|c|c|c|}
\hline Production & Beneficiary & Non beneficiary & CR Ratio \\
\hline Category & P1 & P2 & \\
\hline Low(\%) & $10.0(\mathrm{n} 1=150)$ & $45.3(\mathrm{n} 2=150)$ & $5.668^{* *}$ \\
\hline Medium(\%) & $11.3(\mathrm{n} 1=150)$ & $39.3(\mathrm{n} 2=150)$ & $6.206^{* *}$ \\
\hline High(\%) & $78.7(\mathrm{n} 1=150)$ & $15.3(\mathrm{n} 2=150)$ & $3.305^{* *}$ \\
\hline $\begin{array}{l}\text { *-(P<0.05)-Level of significant found to be 95\%, } \\
\text { significant }\end{array}$ & \multicolumn{2}{|l|}{$<\mathbf{0 . 0 1}$ )-Level of significant found to be 99\%,ns- non } \\
\hline
\end{tabular}

Table.3 Production of Up land paddy

\begin{tabular}{|c|c|c|c|}
\hline Production & Beneficiary & Non beneficiary & CR Ratio \\
\hline Category & P1 & P2 & \\
\hline $\operatorname{Low}(\%)$ & $10.0(\mathrm{n} 1=150)$ & $37.3(\mathrm{n} 2=150)$ & $6.649 * *$ \\
\hline Medium(\%) & $15.3(\mathrm{n} 1=150)$ & $43.3(\mathrm{n} 2=150)$ & $5.343^{* *}$ \\
\hline $\operatorname{High}(\%)$ & $74.7(\mathrm{n} 1=150)$ & $19.3(\mathrm{n} 2=150)$ & $3.305^{* *}$ \\
\hline
\end{tabular}

Table.4 Production of Kharif paddy

\begin{tabular}{|c|c|c|c|}
\hline Production & Beneficiary & Non beneficiary & CR Ratio \\
\hline Category & P1 & P2 & \\
\hline $\operatorname{Low}(\%)$ & 7.3(n1=150) & $38.0(\mathrm{n} 2=150)$ & $6.949 * *$ \\
\hline Medium(\%) & $12.7(\mathrm{n} 1=150)$ & $32.7(\mathrm{n} 2=150)$ & $6.934 * *$ \\
\hline $\operatorname{High}(\%)$ & $80.0(\mathrm{n} 1=150)$ & $29.3(\mathrm{n} 2=150)$ & $2.841 \mathrm{~ns}$ \\
\hline
\end{tabular}


Table.5 Production of Rabi paddy

\begin{tabular}{|c|c|c|c|}
\hline Production & Beneficiary & Non beneficiary & CR Ratio \\
\hline Category & $\mathrm{P} 1$ & $\mathrm{P} 2$ & \\
\hline Low $(\%)$ & $9.3(\mathrm{n} 1=150)$ & $42.7(\mathrm{n} 2=150)$ & $6.036^{* *}$ \\
\hline Medium(\%) & $14.7(\mathrm{n} 1=150)$ & $36.7(\mathrm{n} 2=150)$ & $6.107^{* *}$ \\
\hline High(\%) & $76.0(\mathrm{n} 1=150)$ & $20.7(\mathrm{n} 2=150)$ & $3.219^{*}$ \\
\hline *-(P $\left.^{*}<0.05\right)-$ Level of significant found to be $95 \%,{ }^{* *}-(\mathrm{P}<0.01)-$ Level of significant found to be $99 \%$, ns- non significant \\
\hline
\end{tabular}

Table.6 Productivity of low land paddy

\begin{tabular}{|c|c|c|c|}
\hline Productivity & Beneficiary & Non beneficiary & CR Ratio \\
\hline Category & $\mathrm{P} 1$ & P2 & \\
\hline Low $(\%)$ & $6.7(\mathrm{n} 1=150)$ & $40.7(\mathrm{n} 2=150)$ & $6.634^{* *}$ \\
\hline Medium(\%) & $13.3(\mathrm{n} 1=150)$ & $34.0(\mathrm{n} 2=150)$ & $6.649^{* *}$ \\
\hline High(\%) & $80(\mathrm{n} 1=150)$ & $25.3(\mathrm{n} 2=(150)$ & $2.950^{*}$ \\
\hline *-(P<0.05)-Level of significant found to be $95 \%, * *-(\mathrm{P}<0.01)$-Level of significant found to be $99 \%$, ns- non significant \\
\hline
\end{tabular}

Table.7 Productivity of medium land paddy

\begin{tabular}{|c|c|c|c|}
\hline Productivity & Beneficiary & Non beneficiary & CR Ratio \\
\hline Category & $\mathrm{P} 1$ & $\mathrm{P} 2$ & \\
\hline Low(\%) & $8.0(\mathrm{n} 1=150)$ & $44.0(\mathrm{n} 2=150)$ & $6.036^{* *}$ \\
\hline Medium(\%) & $14.7(\mathrm{n} 1=150)$ & $36.0(\mathrm{n} 2=150)$ & $6.193^{* *}$ \\
\hline High(\%) & $77.3(\mathrm{n} 1=150)$ & $20.0(\mathrm{n} 2=150)$ & $3.195^{*}$ \\
\hline *-(P<0.05)-Level of significant found to be $95 \%, * *$-(P<0.01)-Level of significant found to be $99 \%$, ns- non significant \\
\hline
\end{tabular}

Table.8 Productivity of Up land paddy

\begin{tabular}{|c|c|c|c|}
\hline Productivity & Beneficiary & Non beneficiary & CR Ratio \\
\hline Category & $\mathrm{P} 1$ & $\mathrm{P} 2$ & $6.36^{* *}$ \\
\hline Low(\%) & $8.7(\mathrm{n} 1=150)$ & $40.7(\mathrm{n} 2=150)$ & $5.808^{* *}$ \\
\hline Medium(\%) & $16.0(\mathrm{n} 1=150)$ & $38.0(\mathrm{n} 2=150)$ & $3.219^{*}$ \\
\hline High(\%) & $75.3(\mathrm{n} 1=150)$ & $21.3(\mathrm{n} 2=150)$ & ( $)$ \\
\hline \multirow{2}{*}{$*(\mathrm{P}<0.05)$-Level of significant found to be $95 \%, * *-(\mathrm{P}<0.01)$-Level of significant found to be $99 \%$, ns- non significant } \\
\hline
\end{tabular}

Table.9 Productivity of Kharif paddy

\begin{tabular}{|c|c|c|c|}
\hline Productivity & Beneficiary & Non beneficiary & CR Ratio \\
\hline Category & $\mathrm{P} 1$ & $\mathrm{P} 2$ & \\
\hline Low(\%) & $6.7(\mathrm{n} 1=150)$ & $40.0(\mathrm{n} 2=150)$ & $6.736^{* *}$ \\
\hline Medium(\%) & $10.7(\mathrm{n} 1=150)$ & $32.0(\mathrm{n} 2=150)$ & $7.383^{* *}$ \\
\hline High(\%) & $82.6(\mathrm{n} 1=150)$ & $28.0(\mathrm{n} 2=150)$ & $2.808 \mathrm{~ns}$ \\
\hline *-(P<0.05)-Level of significant found to be $95 \%, * *$-(P<0.01)-Level of significant found to be $99 \%$, ns- non significant \\
\hline
\end{tabular}


Table.10 Productivity of Rabi paddy

\begin{tabular}{|c|c|c|c|}
\hline Productivity & Beneficiary & Non beneficiary & CR Ratio \\
\hline Category & $\mathrm{P} 1$ & $\mathrm{P} 2$ & \\
\hline Low $(\%)$ & $11.3(\mathrm{n} 1=150)$ & $42.0(\mathrm{n} 2=150)$ & $5.885^{* *}$ \\
\hline Medium(\%) & $12.0(\mathrm{n} 1=150)$ & $32.0(\mathrm{n} 2=150)$ & $7.160^{* *}$ \\
\hline High(\%) & $76.7(\mathrm{n} 1=150)$ & $26.0(\mathrm{n} 2=150)$ & $3.026^{*}$ \\
\hline *-(P $\left.^{*}<0.05\right)-$ Level of significant found to be $95 \%,{ }^{* *}-(\mathrm{P}<0.01)-$ Level of significant found to be $99 \%$, ns- non significant \\
\hline
\end{tabular}

Therefore, it is concluded by the researcher that the line dept. officials and other extension functionaries had properly provided training and technology demonstration programme to all the productivity category of BGREI farmers.

\section{Productivity of Up land paddy}

BGREI beneficiaries and non beneficiaries are distributed according to productivity of $\mathrm{Up}$ land paddy in their farm.

Beneficiaries $(\mathrm{N})=150$, Non beneficiaries $(\mathrm{N})=150$

The table shows the percentage of productivity of Up land paddy along with level of significant difference in productivity of Up land paddy among BGREI beneficiary and non beneficiary farmers. It was observed that, among low, medium and high productivity category beneficiary and non beneficiary farmers there is significant difference in productivity with critical ratio $6.36^{* *}, 5.808^{* * *}$ and 3.219* respectively. So there is significant impact by BGREI on all the productivity category of beneficiary farmers.

Therefore, it is concluded by the researcher that the line dept. officials and other extension functionaries had properly provide training and technology demonstration programme to all the productivity category of BGREI farmers.

\section{Productivity of Kharif paddy}

BGREI beneficiaries and non beneficiaries are distributed according to productivity of kharif paddy in their farm.

Beneficiaries $(\mathrm{N})=150$, Non beneficiaries $(\mathrm{N})=150$

The table shows the percentage of productivity of kharif paddy along with level of significant difference in productivity of kharif paddy among BGREI beneficiary and non beneficiary farmers. It was observed that, among low and medium productivity category beneficiary and non beneficiary farmers there is significant difference in productivity with critical ratio $6.736^{* *}$ and $7.383^{* *}$ respectively. So there is significant impact by BGREI on low and medium productivity category beneficiary farmers. But in high category CR found to be 2.808, among BGREI beneficiary and non beneficiary farmers with no significant difference in productivity.

Therefore, it is suggested by the researcher that the line dept. officials and other extension functionaries should provide training and technology demonstration programme to high productivity category BGREI farmers.

\section{Productivity of Rabi paddy}

BGREI beneficiaries and non beneficiaries are distributed according to productivity of rabi paddy in their farm. 
Beneficiaries $(\mathrm{N})=150$, Non beneficiaries $(\mathrm{N})=150$

The table shows the percentage of productivity of rabi paddy along with level of significant difference in productivity of rabi paddy among BGREI beneficiary and non beneficiary farmers. It was observed that, among low, medium and high productivity category beneficiary and non beneficiary farmers there is significant difference in productivity with critical ratio $5.885^{* *}$, $7.160^{* *}$ and $3.026^{* *}$ respectively. So there is significant impact by BGREI on all the productivity category beneficiary farmers.

Therefore, it is concluded by the researcher that the line dept. officials and other extension functionaries had properly provide training and technology demonstration programme to all the productivity category of BGREI farmers.

There was an increase in knowledge on rice production technology of the almost all the category of beneficiary farmers after participating in the programme and there was a positive impact of BGREI programme on the productivity of rice of the beneficiary farmers. This programme is a farmer friendly programme and it should be continued to improve and sustain the livelihood of farmers.

\section{Acknowledgements}

I am sincerely thankful to the following for their valuable research support: Dr. B. P. Mohapatra, Dr. S. P. Sangramsingh, Dr. B. P.
Mishra, Dr. P. K. Banerjee, Dr. R. S. Panigrahi and also to Department of Extension Education, Odisha University of Agriculture and Technology, Krishi Vigyan Kendra, Sambalpur, Chief District Agriculture Office, Sambalpur.

\section{References}

Gogai, S. K and Phukan, C. 2000. Extent of adoption of improved rice cultivation practices by farmers. Maharastra Journal of Extension Education, 19: 117-120.

Hile, R. B., Sanap, D. J., and Shrote, R. V.2015. Adoption and impact assessment of production technology of paddy in Marathwada region of Maharashtra. International Journal of Agriculture Sciences. 7(11): 767-773.

Meena S L, Lakhera, J P. Sharma, K. C. and Johri, S. K. 2012. Knowledge Level and Adoption Pattern of rice production technology among farmers. Raj. J. Extn. Edu., 20: 133-137.

Rao, G. A., Gowda, N. S. and Geetha, K. 2001. Suggestions for farmers in achieving sustainability of rice farming and agricultural sustainability. Current Research 30(11-12): 171-174

Samarpitha, A., Vasudev, N., Suhasini, K., Rao, I. S. and Bhave, M. H. 2016. An insight into socio-economic profile of rice farmers: exploration from Kurnool district of Andhra Pradesh. International Journal of Food, Agriculture and Veterinary Sciences, 6(1): 1-6.

\section{How to cite this article:}

Anannya Jena. 2021. A Study to Compare the Production and Productivity of Rice Crop Between the BGREI Beneficiary Farmers and Non-Beneficiary Farmers in Odisha. Int.J.Curr.Microbiol.App.Sci. 10(09): 97-104. doi: https://doi.org/10.20546/ijcmas.2021.1009.011 